\title{
Poor readers' use of orthographic information in learning to read new words: A visual bias or a phonological deficit?
}

\author{
Alan M. McNeIl \\ University of St. Andrews, St. Andrews, Scotland \\ AND \\ RHONA S. JoHNSTON \\ University of Hull, Hull, England
}

\begin{abstract}
In this study, we examined the ability of 11-year-old poor readers and reading age controls to learn new print vocabulary. It was found that the poor readers were slower than the controls to learn to read a set of nonwords accurately but that, when asked to pick out the nonwords in a visual recognition memory task, they reached criterion much more quickly than did the controls. However, when the groups were compared on auditory recall of the items being learned, the poor readers were at a disadvantage. Thus, the poor readers developed a visual store for the nonwords more quickly than did the controls but were slower to establish phonological representations for the nonwords. It was concluded that the poor readers were slower to establish a form of sight word reading that was well underpinned in memory by connections between the letters in the spelling and the phonemes in the pronunciation, suggesting that they had a greater reliance on an orthographic-semantic pathway in word recognition than did the controls.
\end{abstract}

It has been shown in many tasks that poor readers' visual skills are unimpaired, their recall of nonsense pictures, abstract shapes (McDougall, Hulme, Ellis, \& Monk, 1994; Swanson, 1984, 1987) and letters from an unfamiliar orthography (Vellutino, Pruzek, Steger, \& Meshoulam, 1973) being appropriate for chronological age. On the other hand, in the phonological domain, poor readers have been found to have impaired verbal short-term memories (Brady, Shankweiler, \& Mann, 1983; Jorm, 1983), difficulty in reading nonwords (Baddeley, Ellis, Miles, \& Lewis, 1982; Snowling, 1981), and problems in carrying out phonemic and phonological awareness tasks (Bruck \& Treiman, 1990; Jorm \& Share, 1983; Manis, Custodio, \& Szeszulski, 1993; Stanovich, Cunningham, \& Cramer, 1984). It has been concluded that poor readers encounter difficulty in the visual domain only when visual stimuli have to be named (Ellis, 1981; Swanson, 1984; Vellutino et al., 1973) or when they are required to integrate visual and verbal codes (Swanson, 1987; Vellutino, 1979).

As far as reading is concerned, the ability to read phonologically has largely been gauged by tasks generated by the dual-route model of reading (Coltheart, 1978). This posits the existence of a direct visual (i.e., lexical) route to reading and an indirect phonological (i.e., sublexical) route. Regular words (e.g., hand) can be read by either route, whereas it has been argued that irregular words (e.g., glove) can be read only by the direct visual route.
Therefore, an advantage in reading regular versus irregular words shows that the reader is using phonological information to recognize words, in addition to the information generated by the visual route. It has indeed been found that performance on regular and irregular words can be differentiated, in children and in adults. Waters, Seidenberg, and Bruck (1984) found regularity effects in Grade 5 children, but the effects were more pervasive in younger and less mature readers. Regularity effects are still found to occur in the reading of adults, but by this stage, regularity effects are less pronounced and are more likely to be found only in reaction time data, since accuracy is usually at ceiling (Seidenberg, Waters, Barnes, \& Tanenhaus, 1984). As the word forms become more familiar, therefore, the direct visual route comes to predominate in skilled adult reading. As far as poor readers are concerned, in most studies, their regularity effects have been of the same magnitude as those of their reading age (RA) controls (Metsala, Stanovich, \& Brown, 1998), although there have been a few exceptions to this (e.g., Beech \& Awaida, 1992; Johnston, Anderson, Perrett, \& Holligan, 1990).

Another way of testing for the ability to take a phonological approach to reading is the nonword reading task, in which novel letter strings (e.g., brank) are read in order to gauge how efficiently this route operates. Although regular words have been used to gauge phonological reading skill, these items can also be read visually. However, non-

R. S. Johnston, r.s.johnston@hull.ac.uk 
words do not have lexical representations, so performance can result only from sublexical segmentation of the letter string. A substantial number of studies have shown poor readers to be less accurate at reading nonwords for RA, but it has to be noted that there are also studies that have not shown this impairment (see Rack, Snowling, \& Olson, 1992, for a review). Given that, in these studies, poor readers are generally matched with RA controls on word recognition ability, if they are impaired in nonword reading ability, this implies that their word recognition skills have been acquired using more visual- or word-specific information than that of controls.

It is of interest, therefore, that there is some evidence that poor readers use a more visual or orthographic approach in reading than do controls (e.g., Foorman \& Liberman, 1989; Seymour \& Porpodas, 1980; Snowling, 1980). However, it is not known whether this is due to poor readers' compensating for having difficulty in taking a phonological approach to reading or whether they take a visual approach because their visual skills are unimpaired for chronological age and, so, are good for their RA. Manis, Seidenberg, Doi, McBride-Chang, and Petersen (1996) found phonological dyslexics to be impaired on a phoneme position analysis task, but not on an orthographic choice task, in which a pseudohomophone was used as a foil (e.g., rane vs. rain). There is a problem, however, in determining what is consequence and what is cause. Difficulty in learning to take a graphemeto-phoneme approach in reading may, indeed, stem from impaired phonological representations, but taking a visual or orthographic approach to reading may, by itself, lead to a failure to establish adequate visual-phonological linkages and, so, result in impaired phonological reading skills. Such propositions may usefully be conceptualized within a connectionist model, such as that of Harm and Seidenberg (2004), whereby two interacting pathways operate. Poor readers might suffer an impairment in the orthographic-phonological-semantic pathway but, on the other hand, might, in fact, have a rather better functioning orthographic-semantic pathway than do RA controls. If the latter is the case, one may predict that poor readers would be biased toward using orthographic codes in memory tasks, and indeed, there is evidence to this effect.

Holligan and Johnston (1988) found that after children had seen lists of rhyming and nonrhyming word pairs, in a subsequent recognition memory test, the poor readers demonstrated a bias toward the selection of orthographically similar word pairs (e.g., post-cost), whereas normal readers made proportionately more choices on the basis of the shared phonological properties of rhyming words (e.g., food-rude). Even more striking is Rack's (1985) finding that poor readers had better recall of orthographically similar pairs than of orthographically dissimilar pairs even when the mode of presentation was auditory, which was not the case for the normal readers. Such findings may be due to impairments in the representation and use of phonological information. However, although individual differences in levels of phonological representation will undoubtedly be the cause of poor reading in some children, it is interesting that some children (e.g., phonological dyslexics) are not equally impaired on all aspects of word reading. One question, therefore, is why are certain aspects of reading affected and not others? One way to respond to this question is to examine patterns of behavior observed in children during reading acquisition, to examine whether such findings arise because of superior visual skills in poor readers.

We examined the approach that 11-year-old poor readers took to learning new print vocabulary - that is, nonwords - to see whether it would differ qualitatively from that of RA controls. It is possible that in the initial stages of print word learning, poor readers' emphasis may be on the visual form of words, whereas RA controls may be better at developing phonological representations for the new items and at developing connections between the visual and the phonological forms. This led to the prediction that poor readers would be better able than controls to identify nonwords being learned in a visual recognition task but would have impaired auditory memory for the items. They should also show slower improvement in their ability to learn to pronounce the nonwords accurately. We also examined performance on a regularity task and on phonemic awareness and rhyme judgment tasks. It was predicted that if the poor readers were suffering from a phonological reading disorder, they would show a smaller regular word advantage, as compared with controls, and that their underlying phonological awareness skills would also be impaired.

\section{METHOD}

\section{Participants}

Thirty-seven children in total were studied. Eighteen of these children were identified as having specific reading disability and were attending a reading unit for intensive remedial tuition twice weekly for half-day periods. Children had been selected to attend the unit on the basis of having IQs of 90 and above. Participation in the study required that each poor reader have an RA that was at least 2 years behind his/her chronological age. The RA control children were required to have RAs appropriate for chronological age. The two ability groups were matched on the British Abilities Scales (BAS) Test of Word Reading (Elliott, Murray, \& Pearson, 1977). IQ was measured by the four-test short form (Maxwell, 1959) of the Wechsler Intelligence Scale for Children (WISC-R; Wechsler, 1974) as prorated by the method adopted by Sattler (1982), using the Similarities, Vocabulary, Block Design, and Object Assembly subtests. The characteristics of these groups are presented in Table 1.

\section{Procedure}

The participants were individually tested, and the order of presentation of the tasks was randomized. One experimental task was assigned to each session.

\section{Nonword Acquisition Task}

The stimuli consisted of four sets of six nonwords, presented (individually) in 28-point font on index cards. Only one set of these was used per child. The choice of the set used was counterbalanced across participants, within groups. (The stimulus sets are shown in Appendix A.) Three of the six nonwords in a set shared a common orthographic pattern (e.g., oa in gaboatok, gapoatok, and ganoatok), and three were individually unique (e.g., ou, oi, and $a i$ in renoudel, yamoiter, and nuraipog, respectively). The purpose of having one of the vowel digraphs repeated in three out of the six nonwords was to examine whether there would be faster rates of word learning for these stimuli due to the common orthographic (i.e., repeated spelling) pattern. In order to control for possible vowel digraph effects (e.g., $o a$ being better known than $o i$ ), oa, ou, oi, or $a i$ was repeated three times 
Table 1

Participant Characteristics

\begin{tabular}{|c|c|c|c|c|c|c|c|c|c|c|c|}
\hline \multirow[b]{2}{*}{ Group } & \multirow[b]{2}{*}{$n$} & \multicolumn{2}{|c|}{$\mathrm{CA}$} & \multicolumn{2}{|c|}{ RA } & \multicolumn{2}{|c|}{ IQ } & \multicolumn{2}{|c|}{ P-IQ } & \multicolumn{2}{|c|}{ V-IQ } \\
\hline & & $M$ & $S D$ & $M$ & $S D$ & $M$ & $S D$ & $M$ & $S D$ & $M$ & $S D$ \\
\hline or readers & 18 & 12.01 & 0.729 & 8.12 & 1.04 & 09.25 & 11.94 & 107.21 & 14.26 & 109.60 & 11.61 \\
\hline RA controls & 19 & 7.58 & 0.328 & 8.14 & 0.509 & 106.17 & 9.30 & 105.87 & 8.95 & 103.56 & 11.65 \\
\hline
\end{tabular}

Note - CA, chronological age; RA, reading age; P-IQ, performance IQ (Block Design/Object Assembly subtest); V-IQ, verbal IQ (Vocabulary/Similarities subtest).

in each of the four different stimulus sets, the remaining digraphs appearing once. Pilot work showed that children of this reading level have some difficulty in accurately reading vowel digraphs, so both groups had their attention drawn to the vowel digraphs during the training procedure, and corrective feedback was given. The order of presentation of these sets was counterbalanced across participants.

The structure of a typical session included a pretest, consisting of (1) measurement of reading ability for the four vowel digraphs presented in isolation without feedback and then (2a) the children's reading each of the six nonwords, followed by $(2 \mathrm{~b})$ the experimenter's covering up all except the vowel digraph in each nonword and correcting any errors of pronunciation made. This was followed by a series of training and testing trials (maximum $=6$ ), in which the children received practice in reading the (3a) nonwords and ( $3 b)$ digraphs on each trial with feedback, before being tested on (4a) auditory (free) recall, (4b) visual recognition memory, and (4c) nonword reading. These stages (numbered in parentheses above) will now be described in broader procedural detail.

\section{Pretest}

For the procedure, Set 1 (gaboatok, ganoatok, gapoatok, renoudel, yamoiter, and nuraipog) will be used as an example.

1. Vowel digraph reading ability. The child read $a i, o u, o i$, and $o a$ presented in isolation on separate cards. No corrective feedback was given on digraph reading at this stage, since this was likely to assist accuracy in nonword reading ability tested in Step 2a below.

\section{Nonword and vowel digraph learning.}

a. Nonword reading ability. The child attempted to read one of the nonwords, (e.g., gaboatok); the experimenter corrected the child until the item was repeated correctly. Performance on the first attempt was later used as a measure of nonword reading ability. The purpose of feedback at this stage was to ensure that each child was capable of repeating the phonology of an item prior to training and testing trials.

b. Vowel digraph reading ability. The experimenter covered all of the nonword except for $o a$. The child read the vowel digraph in isolation; if incorrect, the child was given the correct pronunciation. Steps $2 \mathrm{a}$ and $2 \mathrm{~b}$ were repeated with the five other nonwords for this set, selected in random order. The purpose of feedback at this stage was to provide some form of pretraining in order to shorten the number of training trials and to familiarize the children with the structure of the training trials to come.

\section{Training and Testing Trials (Maximum $=6$ )}

This differed from Step 2 in that a training session for the six nonwords was always followed by the posttesting of auditory and visual memory and of nonword reading (see Step 4 below).

a. Nonword reading. One nonword was selected randomly (e.g., renoudel), and the child was asked to read it. If correct, the child was asked to reread it for practice. If incorrect, the experimenter read it, and then the child read it. No further feedback was given for a second incorrect reading.

b. Vowel digraph reading. Then experimenter covered all except $o u$ for the child to read. If incorrect, the child received the correct pronunciation.

Steps $3 \mathrm{a}$ and $3 \mathrm{~b}$ were repeated for the remaining five nonwords. There was then a 3-min rest involving discussion of, for example, sports, hobbies, school events, and so forth.

\section{Posttesting After Each Training Session}

a. Auditory memory. The child was asked whether he or she could remember any of the nonwords being learned. The purpose of this measure was to track the development of phonological traces for the items being taught. A score of 1 was awarded for each correctly recalled nonword. Testing stopped when criterion was reached on both the visual recognition memory and nonword reading tasks (see below).

b. Visual recognition memory. Five cards were set out in random order: one target and four distractors - for example, renoudel, renuodel, renoodel, tenoudel, renodek (see Appendix B). The child was asked to pick out the one that he or she had read earlier.

c. Nonword reading. The child was asked to read the choice made in Step 4b. (If the incorrect item had been chosen, the correct target item was presented for reading.) Steps $4 \mathrm{~b}$ and $4 \mathrm{c}$ were then repeated for each of the remaining five nonwords. This was followed by a 2 -min rest.

Training and posttesting continued for up to six trials or until criterion was reached. The criterion for terminating the posttest/ training cycle was based on visual recognition and nonword reading performance, but not on auditory memory. Criterion was the correct selection of each of the six trained nonwords in the visual recognition task (4b) and correct reading of these nonwords (4c) on two consecutive trials. The children would then receive full credit for outstanding trials.

\section{Reading and Phonological Awareness Tasks}

Regularity task. The regularity task was used to assess whether the poor readers took a phonological approach to reading - that is, would the size of their advantage in reading regular versus irregular words be similar to that of RA controls? The stimuli were based on the items used by Waters et al. (1984). They consisted of 56 monosyllabic words, which were divided into four categories of 14 highfrequency regular words (mean frequency $=507.6, S D=413.5$ ), 14 low-frequency regular words $(25.9, S D=21.6), 14$ high-frequency irregular words $(504.4, S D=421.7)$, and 14 low-frequency irregular words $(28.1, S D=23.3)$. Frequencies were gauged according to the Carroll, Davies, and Richman (1971) Grade 3 norms. Test items are presented in Appendix C.

The words were presented one at a time in the center of a computer screen in large lowercase letters. The order of presentation of the words was varied, with no more than three items of the same type appearing in sequence. Six practice items (consisting of three regular and three irregular words) were given prior to the commencement of the test trials. Corrective feedback was given only on practice items. The children were instructed to read the words as quickly and accurately as possible. A voice key was used to measure latencies.

Auditory rhyme judgment. The auditory rhyme judgment task was used to assess overall rhyme ability. There was an additional interest in examining the degree to which rhyme judgment skill would be affected by orthographic similarity, as had been the case with print versions of the task (Holligan \& Johnston, 1988; Rack, 1985). The stimuli were adopted from Duncan and Johnston (1999) and consisted of 60 rhyming and nonrhyming monosyllabic word pairs categorized according to the following four structural properties: (1) orthographically similar rhyming word pairs (e.g., gown-down); (2) orthographically dissimilar rhyming word pairs (e.g., clue-flew); (3) orthographically similar nonrhyming word pairs (e.g., post-lost); 
and (4) orthographically dissimilar nonrhyming word pairs (e.g., hope-goat). The experimenter read out each word pair, and the child's task was to state whether or not the words rhymed. Four practice trials were given prior to the test trials. Corrective feedback was provided only on practice items. The word pairs were presented in a fixed random order from one of four created lists that were counterbalanced across participants. Test items are presented in Appendix D.

Phoneme deletion. The phoneme deletion task used in this study (Duncan \& Johnston, 1999) comprised 24 one-syllable words and 24 one-syllable nonwords. The task was selected because phoneme deletion ability has been found to be the best measure of compound phonemic awareness skills in young children (Yopp, 1988). The test items were counterbalanced for the deletion of initial and final phonemes and for single consonants and consonants as part of a blend. Four different orders of testing were used. The experimenter first read each word or nonword. The child was required to pronounce each item in order to ensure that it had been heard correctly. Thus, the experimenter would say, "say 'desk'." The child would then be asked, "What would be left if we took away the 'kuh' sound?" Prior to the administration of test items, each child was given eight practice items (four words and four nonwords covering the range of segmentation types), the first of which was segmented by the experimenter. Corrective feedback was provided on these practice items. No feedback was given on the test items. The stimuli are presented in Appendix E.

\section{RESULTS}

\section{Nonword Acquisition Task}

\section{Pretest}

1. Vowel digraph reading ability. An analysis was made at pretest of the total number of correctly read vowel digraphs (e.g., ou, ai, oa, and oi). A one-way ANOVA was conducted on these data, with one between-subjects factor: group (poor readers vs. RA controls). The analysis showed no between-groups differences $[F(1,36)=1.83$, $p>.10]$. The means and standard deviations are presented in Table 2.

Data in each of the following analyses were analyzed by a two-way repeated measures ANOVA, involving one between-subjects factor (group: poor readers vs. RA controls) and one within-subjects factor (word type: orthographically similar vs. orthographically dissimilar stimuli).

2. Nonword reading ability. In order to assess nonword reading ability, the first attempt at reading the nonwords was analyzed. The total number of correctly read nonwords formed the dependent variable. The means and standard deviations are presented in Table 2.

The main effect of group was significant $[F(1,35)=$ $4.25, p<.05]$. This was a result of the RA controls' first reading of the nonwords being more accurate than that of the poor readers. There were no differences in accuracy for the reading of orthographically similar stimuli and that of orthographically dissimilar items $[F(1,35)=0.74, p>$ .10]. The group $\times$ word type interaction was not significant $[F(1,35)=0.74, p>.10]$.

\section{Posttesting}

Training and posttesting were terminated when criterion was reached on both the visual recognition and the nonword reading tasks (Step 4 in the Procedure section). Two poor readers and two RA controls reached criterion by the fourth trial; the remaining children carried out all six training and posttest trials. Thus, although many of the children actually reached criterion on one of the two tasks prior to this, all six training and posttest trials were carried out, because criterion had not been reached on the other task. An analysis was made of the number of trials needed to reach criterion on each specific posttest task carried out at the end of each training session.

4a. Auditory memory. Although criterion was set according to performance on the visual recognition and nonword reading tasks, no child on any trial recalled all six nonwords correctly on the auditory memory task. The total number of correctly recalled nonwords for each category (orthographically similar vs. orthographically dissimilar) was calculated and converted to percentage form. The means and standard deviations are presented in Table 3.

The main effect of group was significant $[F(1,35)=$ $6.84, p<.05]$. This was a result of the RA controls' recalling proportionately more items, overall, than did the poor readers. Thus, the controls would appear to have had faster rates of learning in terms of establishing phonological codes for words being learned. The analysis also showed a main effect of word type as a result of fewer presentations being required to enhance recall of orthographically similar nonwords, relative to orthographically dissimilar items $[F(1,35)=18.17, p<.01]$. The interaction between group and word type was not significant $[F(1,35)=0.16$, $p>.10]$.

4b. Visual recognition memory. The total number of trials to criterion for each category of nonword (orthographically similar vs. orthographically dissimilar) formed the dependent variable. The means and standard deviations are presented in Table 3.

The main effect of group was significant as a result of poor readers having fewer trials to criterion than did controls in the selection of target stimuli in the visual recognition memory task $[F(1,35)=26.72, p<.001]$. There was no significant main effect of word type $[F(1,35)=0.042$,

Table 2

Mean Numbers and Percentages of Correctly Identified Vowel Digraphs and Orthographically Similar (OS) Versus Orthographically Dissimilar (OD) Nonwords in the Pretest (Introductory) Stage (With Standard Deviations)

\begin{tabular}{|c|c|c|c|c|c|c|c|c|c|c|c|c|}
\hline \multirow[b]{3}{*}{ Group } & \multicolumn{4}{|c|}{ Vowel Digraph } & \multicolumn{4}{|c|}{ OS Nonword } & \multicolumn{4}{|c|}{ OD Nonword } \\
\hline & \multicolumn{2}{|c|}{$\mathrm{N}$} & \multicolumn{2}{|c|}{$\%$} & \multicolumn{2}{|c|}{$\mathrm{N}$} & \multicolumn{2}{|c|}{$\%$} & \multicolumn{2}{|c|}{$\mathrm{N}$} & \multicolumn{2}{|c|}{$\%$} \\
\hline & $M$ & $S D$ & $M$ & $S D$ & $M$ & $S D$ & $M$ & $S D$ & $M$ & $S D$ & $M$ & $S D$ \\
\hline Poor readers & 1.33 & 1.19 & 33.33 & 0.30 & 0.556 & 0.856 & 18.52 & 0.29 & 0.278 & 0.575 & 9.26 & 1.92 \\
\hline Controls & 1.89 & 1.33 & 47.30 & 0.32 & 0.895 & 0.994 & 29.82 & 0.31 & 0.895 & 0.937 & 29.82 & 0.31 \\
\hline
\end{tabular}

Note- $\mathrm{N}$, frequency (maximum of 4 for vowel digraphs and 3 for nonwords). 
Table 3

Mean Percentages of Correctly Recalled Nonwords in Auditory Recall (AR) and Mean Numbers of Trials to Criterion (Maximum = 6) in the Selection of Target Stimuli on the Visual Recognition Memory (VRM) Task and the Reading of Target Stimuli (RTS) (With Standard Deviations)

\begin{tabular}{|c|c|c|c|c|c|c|c|c|c|c|c|c|}
\hline \multirow[b]{3}{*}{ Group } & \multicolumn{4}{|c|}{ AR } & \multicolumn{4}{|c|}{ VRM } & \multicolumn{4}{|c|}{ RTS } \\
\hline & \multicolumn{2}{|c|}{ OS } & \multicolumn{2}{|c|}{ OD } & \multicolumn{2}{|c|}{ OS } & \multicolumn{2}{|c|}{ OD } & \multicolumn{2}{|c|}{ OS } & \multicolumn{2}{|c|}{ OD } \\
\hline & $M$ & $S D$ & $M$ & $S D$ & $M$ & $S D$ & $M$ & $S D$ & $M$ & $S D$ & $M$ & $S D$ \\
\hline Poor reader & 15.74 & 21.33 & 5.56 & 8.58 & 1.04 & 1.66 & 1.11 & 1.71 & 2.63 & 1.01 & 3.48 & 1.95 \\
\hline Controls & 21.62 & 18.86 & 14.91 & 10.24 & 3.75 & 1.74 & 3.77 & 1.76 & 1.01 & 1.62 & 1.60 & 0.78 \\
\hline
\end{tabular}

Note - OS, orthographically similar; OD, orthographically dissimilar.

$p>$.10]. The interaction between group and word type was not significant $[F(1,35)=0.016, p>.10]$.

4c. Nonword reading. The total number of trials to criterion for orthographically similar versus orthographically dissimilar items was calculated. The means and standard deviations are presented in Table 3.

The main effect of group was significant as a result of the controls' having fewer trials to criterion than did the poor readers in the reading of nonword target stimuli $[F(1,35)=$ $11.22, p<.01]$. The analysis also showed a significant main effect of word type as a result of orthographically similar nonwords being learned in fewer trials than were orthographically dissimilar nonword stimuli $[F(1,35)=$ $7.72, p<.01]$. The interaction between group and word type was not significant $[F(1,35)=0.281, p>.10]$.

\section{Summary of Findings on Nonword \\ Acquisition Task}

Although it was found that the poor readers were slower than the controls to learn to read the set of nonwords accurately and had poorer auditory memory for the items, they were much better at identifying these items in the visual recognition task. It seems, therefore, that the poor readers developed a visual representation of the items more quickly than did their controls but established phonological representations more slowly. The auditory memory impairment, however, may have been a direct consequence of their being less competent at generating a correct reading of the nonwords.

Given that the poor readers showed better visual recognition of the nonwords than did the RA controls, it was necessary to establish whether their word-reading skills also showed evidence of a more visual approach to reading. Furthermore, it was necessary to establish whether there was evidence of their difficulties stemming from an underlying phonological deficit.

\section{Reading and Phonological Awareness Tasks}

\section{Regularity Task}

Accuracy. Two children from the poor reader group were not available for testing. The total number of correctly read words from each of the four categories was calculated and converted to percentage form. These data were analyzed by a three-way repeated measures ANOVA. There was one between-subjects factor (group: poor readers vs. RA controls) and two within-subjects factors (regularity [regular vs. irregular words] and frequency [high- vs. lowfrequency words]). The means and standard deviations are presented in Table 4.

The main effect of group was not significant $[F(1,33)=$ $1.31, p>.10]$. However, there was a main effect of regularity, since more correct responses were given for regular than for irregular words $[F(1,33)=92.37, p<.001]$, and there was an interaction between these two factors $[F(1,33)=$ $7.83, p<.01]$. A Newman-Keuls post hoc analysis of the group $\times$ regularity interaction showed that regular words were read better than irregular words by both the poor reader and the RA control groups $(p<.01)$. However, poor readers were more accurate than controls in the reading of irregular words $(p<.01)$. Their mean regular word advantage was $10.3 \%$, whereas that of the controls was $19.3 \%$.

There was a main effect of frequency, with highfrequency words being read better than low-frequency words $[F(1,33)=156.12, p<.001]$. The group $\times$ frequency interaction approached significance $[F(1,33)=3.70, p=.063]$. None of the other effects was significant $(F>.10)$.

Latency. One RA case was rejected because of missing data due to prematurely triggered voice key responses. The mean reaction times for correctly read items from each of the four categories were calculated, and these data were analyzed in the same manner as above. The means and standard deviations are presented in Table 4.

Table 4

Poor Readers and Reading Age Controls' Mean Percentages of Correct Reading Responses and Reaction Times to Regular and Irregular High- and Low-Frequency Words (With Standard Deviations)

\begin{tabular}{|c|c|c|c|c|c|c|c|c|c|}
\hline \multirow[b]{3}{*}{ Words } & \multirow[b]{3}{*}{ Frequency } & \multicolumn{4}{|c|}{$\%$ Correct } & \multicolumn{4}{|c|}{ Reaction Times } \\
\hline & & \multicolumn{2}{|c|}{ Poor Readers } & \multicolumn{2}{|c|}{ Controls } & \multicolumn{2}{|c|}{ Poor Readers } & \multicolumn{2}{|c|}{ Controls } \\
\hline & & $M$ & $S D$ & $M$ & $S D$ & $M$ & $S D$ & $M$ & $S D$ \\
\hline \multirow[t]{2}{*}{ Regular } & High & 92.21 & 7.86 & 93.18 & 8.47 & $1,830.81$ & 928.78 & $1,275.78$ & 541.59 \\
\hline & Low & 75.77 & 21.91 & 73.19 & 22.88 & $2,344.47$ & $1,158.00$ & $1,657.62$ & 946.18 \\
\hline \multirow[t]{2}{*}{ Irregular } & High & 83.81 & 16.63 & 79.32 & 16.48 & $1,800.16$ & 721.32 & $1,313.16$ & 549.72 \\
\hline & Low & 63.03 & 14.43 & 48.54 & 16.33 & $2,595.29$ & $1,587.12$ & $1,769.38$ & 949.42 \\
\hline
\end{tabular}


The main effect of group was significant, since the RA controls were faster than the poor readers in reading the presented words $[F(1,32)=4.67, p<.05]$. There was no significant main effect of regularity $[F(1,32)=0.78, p>$ $.10]$ and no interaction between these factors $[F(1,32)=$ $0.03, p>.10]$. However, the analysis did show a significant main effect of frequency as a result of high-frequency words being read more quickly than low-frequency words $[F(1,32)=32.55, p<.001]$. The interaction between group and frequency was not significant $[F(1,32)=1.57, p>$ $.10]$. There were no other significant effects $\left(F_{\mathrm{s}}>1\right)$.

Error analysis. Finally, an error analysis was made in order to examine the approaches taken by these groups of readers. Generally speaking, visual errors in regular word reading (e.g., stale for slate) indicate that the reader is viewing words as a whole, rather than making use of lettersound correspondence knowledge (e.g., sounding out), in which case proportionately more nonwords are produced (e.g., slă-tee). Conversely, the application of letter-sound knowledge for unfamiliar irregular words produces regularization errors (e.g., reading steak as steek); visual errors again indicating a whole-word-based approach (e.g., stuck). Two error categories (visual/sounding-out) were used to examine the readers' strategies for regular and irregular words, the latter strategy (category), as it applies to irregular words, being responsible for regularizations.

The percentage of errors for each category formed the dependent variable. These data were analyzed by a threeway repeated measures ANOVA. There was one betweensubjects factor (group: poor readers vs. RA controls) and two within-subjects factors (word type [regular vs. irregular words] and strategy [visual vs. sounding-out]). The means and standard deviations are presented in Table 5.

The analysis showed no significant main effect of group $[F(1,33)=1.04, p>.10]$ but did show one of word type as a result of proportionately more errors' occurring for irregular words $[F(1,33)=7.94, p<.01]$. There was no significant main effect of strategy $[F(1,33)=0.11, p>.10]$. However, a significant interaction occurred between word type and strategy $[F(1,33)=11.53, p<.01]$. Tests of simple effects showed that proportionately more phonological (sounding-out) approaches were made for irregular words $[F(1,69)=10.08, p<.01]$, whereas whole-word (visual) approaches predominated in attempted readings for regular words $[F(1,69)=4.74, p<.05]$. There was also an interaction between group and strategy $[F(1,33)=9.14$, $p<.01]$. Tests of simple effects showed that the poor readers made proportionately more visual (word substitution) errors than did the controls $[F(1,33)=8.14, p<.01]$, whereas the controls showed greater evidence of taking a phonological approach [i.e., had more phonological- and regularization-based errors; $F(1,33)=6.06, p<.05]$.

\section{Auditory Rhyme Judgment}

Although, in their written form, the orthography of some rhyming (e.g., bear-hare) and nonrhyming (e.g., wear-dear) word pairs used in this investigation are not ambiguous, with auditory presentation, it is possible that alternative visual representations might have been retrieved (e.g., bare-hare and wear-deer, respectively). These items (i.e., homonyms) were, therefore, removed prior to analysis. This involved the elimination of four word pairs from the orthographically dissimilar rhyming subset (e.g., pain-lane, tail-pale, bear-hare, and poursore) and three word pairs from the orthographically similar nonrhyming subset (e.g., wear-dear, gone-lone, and pear-year). One child from each of the two groups was unavailable at the time of testing.

The total number of correctly judged word pairs from each of the four classifications was calculated and converted to percentage form. These data were analyzed by a three-way repeated measures ANOVA. There was one between-subjects factor (group: poor readers vs. RA controls) and two within-subjects factors (rhyme [rhyming vs. nonrhyming] and similarity [orthographically similar vs. orthographically dissimilar]). The means and standard deviations are presented in Table 6.

There was a significant main effect of group as a result of the RA controls' performing better than the poor readers $[F(1,33)=4.56, p<.05]$. The analysis also showed a main effect of rhyme, since more correct responses were given for rhyming than for nonrhyming word pairs $[F(1,33)=23.86, p<.001]$. A main effect of similarity was also noted as a result of the judgment of orthographically dissimilar (rhyming and nonrhyming) pairs being better than that of orthographically similar (rhyming and nonrhyming) pairs $[F(1,33)=24.49, p<.001]$. Interactions were found between the factors of group and rhyme $[F(1,33)=4.82, p<.05]$, group and similarity $[F(1,33)=4.76, p<.05]$, and rhyme and similarity $[F(1,33)=25.89, p<.001]$.

A Newman-Keuls post hoc analysis of the group $\times$ rhyme interaction showed that the poor readers were as good as the controls at correctly accepting rhyming word pairs but were much poorer at saying that word pairs did not rhyme. Analysis of the group $\times$ similarity interaction

Table 5

Poor and Normal Readers' Mean Percentages of Whole-Word (W-W) and Sounding-Out (S-Out) Responses in Errors for Regular Words and W-W and Regularization Responses in Errors for Irregular Words (With Standard Deviations)

\begin{tabular}{|c|c|c|c|c|c|c|c|c|}
\hline \multirow[b]{3}{*}{ Group } & \multicolumn{4}{|c|}{ Regular } & \multicolumn{4}{|c|}{ Irregular } \\
\hline & \multicolumn{2}{|c|}{ W-W } & \multicolumn{2}{|c|}{ S-Out } & \multicolumn{2}{|c|}{$\mathrm{W}-\mathrm{W}$} & \multicolumn{2}{|c|}{ S-Out } \\
\hline & $M$ & $S D$ & $M$ & $S D$ & $M$ & $S D$ & $M$ & $S D$ \\
\hline Poor readers & 70.16 & 33.97 & 17.34 & 21.20 & 45.27 & 19.81 & 54.74 & 19.81 \\
\hline Controls & 32.32 & 36.08 & 41.37 & 39.41 & 36.89 & 27.35 & 62.73 & 27.28 \\
\hline
\end{tabular}


Table 6

Poor and Normal Readers' Mean Percentages of Correctly Judged

Orthographically Similar and Orthographically Dissimilar Rhyming and

Nonrhyming Word Pairs (With Standard Deviations)

\begin{tabular}{|c|c|c|c|c|c|c|c|c|}
\hline \multirow[b]{3}{*}{ Group } & \multicolumn{4}{|c|}{ Rhyming } & \multicolumn{4}{|c|}{ Nonrhyming } \\
\hline & \multicolumn{2}{|c|}{ OS } & \multicolumn{2}{|c|}{ OD } & \multicolumn{2}{|c|}{ OS } & \multicolumn{2}{|c|}{ OD } \\
\hline & $M$ & $S D$ & $M$ & $S D$ & $M$ & $S D$ & $M$ & $S D$ \\
\hline Poor readers & 96.86 & 4.78 & 99.07 & 2.65 & 62.35 & 32.55 & 96.47 & 6.29 \\
\hline Controls & 98.52 & 2.85 & 96.97 & 5.40 & 82.87 & 25.48 & 98.52 & 2.85 \\
\hline
\end{tabular}

Note_-OS, orthographically similar; OD, orthographically dissimilar.

showed that the two groups were equally good at making correct decisions on orthographically dissimilar pairs but differed in their performances for orthographically similar pairs.

There was no interaction between group, rhyme, and similarity $[F(1,33)=2.33, p>.10]$. However, it can be seen from the means that the poor readers' problems with orthographically similar word pairs lay in a difficulty in determining that orthographically similar nonrhyming pairs did not rhyme. That is, they were prone to say that pairs of words such as post-cost did rhyme. Since it was predicted from previous research that poor readers would have difficulty with orthographically similar nonrhyming word pairs, a planned $t$ test was carried out. This showed that the poor readers made more errors than did the controls on orthographically similar nonrhyming word pairs $[t(33)=2.8, p<.05]$. None of the other comparisons between poor readers and controls was significant - that is, those on orthographically similar rhyming pairs $[t(33)=$ $0.23, p>.05]$, orthographically dissimilar rhyming pairs $[t(33)=0.3, p>.05]$, or orthographically dissimilar nonrhyming pairs $[t(33)=0.03, p>.05]$.

\section{Phoneme Deletion}

The total number of correct responses to word and nonword stimuli was calculated and converted to percentage form. These data were analyzed by a two-way repeated measures ANOVA. There was one between-subjects factor (group: poor reader vs. RA controls) and one withinsubjects factor (word type: words vs. nonwords). The means and standard deviations are reported in Table 7.

The main effect of group was not significant $[F(1,35)=$ $1.56, p>.10]$. However, the analysis showed a significant main effect of word type $[F(3,105)=10.18, p<.01]$. This was due to children's deletion performance on word stimuli being better than that on nonword items. The group $\times$ word type interaction was not significant $[F(3,105)=0$, $p>.10]$.

\section{DISCUSSION}

It was found that poor readers were better than RA controls at identifying target printed words in a set of distractors in a visual recognition task. However, they read these nonwords less well and had impaired auditory memory for these items. There was evidence that they took a more visual ${ }^{1}$ approach to printed words than did the controls, since they showed a smaller regularity effect and were more influenced by the visual appearance of words in an auditory rhyme judgment task. Given the apparent lack of reliance on phonological information for orthographically similar nonrhyming items in the auditory rhyme judgment task and the poorer auditory recall for items in the nonword acquisition task, it is important to consider whether this pattern of reading performance can be ascribed to an underlying phonological deficit.

Bailey, Manis, Pedersen, and Seidenberg (2004) found, in a task in which children were trained to read nonwords with either regular or irregular pronunciations, that it was the poor readers with weak underlying phonological representations that did not show a regularity effect. However, in the present study, the poor readers did not differ from RA controls in phonemic awareness ability. They showed greater variability in their scores, which might have led to nonsignificance, but the greater variability was caused by just 2 children scoring below the level of the lowest performing RA controls. Thus, most of the poor readers performed within the same range as the RA controls.

In terms of the dual-route model, the poor readers' smaller regularity effects and impaired nonword reading for RA in the present study might be characterized as an impaired phonological reading route and an intact visual/lexical route. The poor readers were found to have better reading of irregular words than did the RA controls. This may have arisen, according to the Harm and Seidenberg (2004) model, due to greater training on the orthographic-semantic pathway because of greater print exposure, which may have led to a more visual approach to word reading (see also Harm \& Seidenberg, 1999; Plaut, McClelland, Seidenberg, \& Patterson, 1996; Seidenberg \& McClelland, 1989). The RA controls may have relied more on the orthographic-phonological semantic pathway for word recognition, which may have disrupted their irregular word reading. The error data are compatible with this account, since the RA controls were found to make significantly more sounding-out errors than did the poor readers, who, in turn, made significantly more whole-

Table 7

Phoneme Deletion: Mean Percentages of Correct Responses to Word and Nonword Stimuli (With Standard Deviations)

\begin{tabular}{|c|c|c|c|c|c|c|}
\hline \multirow[b]{2}{*}{ Group } & \multicolumn{2}{|c|}{ Word } & \multicolumn{2}{|c|}{ Nonword } & \multicolumn{2}{|c|}{ Total } \\
\hline & $M$ & $S D$ & $M$ & $S D$ & $M$ & $S D$ \\
\hline Poor readers & 64.35 & 29.85 & 59.49 & 28.25 & 62.03 & 28.74 \\
\hline Controls & 73.90 & 15.52 & 68.86 & 19.76 & 71.38 & 16.99 \\
\hline
\end{tabular}


word errors (see Table 5). It might have been expected that the deficient orthographic-phonological skills shown by the poor readers on the nonword reading task would also have led to impaired regular word reading. The fact that their regular word reading was RA appropriate suggests that their superior semantic skills made up for their less effective sounding-out skills. That is, as they tried to assemble a pronunciation, they would need less phonological information to activate a word in their spoken vocabularies than would their RA controls. Nonwords lack semantic support and, so, would rely on an orthographicphonological pathway for pronunciation. This pathway might work less efficiently for the poor readers if their underlying phonological skills were impaired, or on the other hand, reliance on a relatively strong orthographicsemantic pathway might lead to a nonword reading deficit. There is some evidence of the poor readers' having a greater reliance on an orthographic-semantic approach to word reading, since they made $38 \%$ more whole-word errors than did the controls in reading regular words and showed a trend in that direction for irregular words.

There is clear evidence that the poor readers relied more on the orthographic, rather than the phonological, structure of novel words and words in both the nonword acquisition and the auditory rhyme judgment tasks. Thus, the poor readers were better able to detect the nonwords than were the RA controls in the visual recognition task, despite having difficulty in learning to pronounce them correctly. Although the poor readers appeared to have deficient auditory rhyme judgment skills, their problems lay in saying that orthographically similar nonrhyming words rhymed (e.g., post-cost), which suggests that they visualized the spoken words and, so, incorrectly identified such pairs of words as rhyming. A number of other studies have, in fact, also shown poor readers to perform better on tests of orthographic processing (e.g., Frith \& Snowling, 1983; Holligan \& Johnston, 1988; Manis et al., 1996; Olson, Kliegl, Davidson, \& Foltz, 1985; Olson, Wise, Connors, Rack, \& Fulker, 1989; Rack, 1985; Siegel, Share, \& Geva, 1995; Stanovich \& Siegel, 1994).

There is evidence that visual and orthographic skills are important predictors of later reading skill. Badian (1994, 1995) has shown that preschoolers who are accurate at distinguishing among visually similar sequences of letters and numerals generally do well in later reading, when automatic recognition of words is crucial for reading fluency and comprehension. However, successful reading involves the establishment of automatic orthographicphonological connections (Adams \& Bruck, 1993; Ehri, 1992), a skill that can be indexed by examining naming speed. It has been shown in kindergarteners that slowness in the naming of letters, numbers, and color patches is one of the best predictors of their future reading abilities (Badian, 1994; Bishop \& Adams, 1990; Scarborough, 1989; Wolf \& Goodglass, 1986). The poor readers in this study had longer reaction times than did their RA controls when reading regular and irregular words, which may reflect problems in the precise timing mechanisms necessary to the integration of orthographic and phonological codes (Bowers \& Wolf, 1993). Imprecise integration of this information would result in difficulties in the development and retrieval of phonological representations from long-term memory and, thus, would contribute to the poor readers' word recognition difficulties. This could, in part, explain their atypical performance and their reliance on orthographic codes.

The results of the present study suggest that the poor readers used a form of memory coding that was qualitatively different from that used by RA controls when learning new print vocabulary. Consequently, their word recognition may have been less well underpinned by connections in memory between the letters in the spelling and the phonemes in the pronunciation (Ehri, 1992). In another study, these same poor readers showed a visual bias in their memory codes for pictorial stimuli (McNeil \& Johnston, 2004). In serial order recall tasks, when children (and adults) encode pictorial information verbally and rehearse the items, they show word length effects (i.e., better recall of short than of long words; Baddeley, Thomson, \& Buchanan, 1975) and phonemic similarity effects (i.e., better recall of phonologically dissimilar than of similar items; Baddeley, 1986). However, with pictorial stimuli, the poor readers from the present study showed no word length effects and showed phonemic similarity effects of reduced magnitude. This suggests that they relied on visual coding with these items. It was indeed found that their performance was disrupted when they were asked to recall visually similar pictures, suggesting that they used a visual strategy to remember the pictures, rather than using the verbal coding preferred by the RA controls. However, when words were presented either auditorily or in print form for recall, the poor readers showed normal phonemic similarity and word length effects. It can be concluded that they did not have deficient phonological coding skills for RA, since they showed normal phonological similarity and word length effects in the nonpictorial versions of the task, but that they used pictorial coding in preference to phonological coding when this was possible. Ordinarily, the use of phonological codes in short-term memory tasks involving pictures increases with age (Hitch, Halliday, Dodd, \& Littler, 1989). Thus, if poor readers show developmental delay (in that they are slow to start encoding pictorial stimuli verbally), one may expect more evidence of their use of phonological codes at a later age. However, there is evidence that older poor readers also fail to show pictorial word length effects and, likewise, continue to be less affected by rhyme than are good readers of the same chronological age (Macaruso, Locke, Smith, \& Powers, 1996).

The findings from the present study, taken together with those of others (Macaruso et al., 1996; McNeil \& Johnston, 2004), may have direct implications for understanding the nature of poor readers' slowness in learning to recognize new words. In normal readers, repeated exposure to words or other printed stimuli that have verbal labels usually leads to the development of interconnections between the visual and the verbal modalities (Swanson, 1987). The present findings suggest that the poor readers' visual and verbal coding systems were poorly interconnected. Thus, when visual stimuli were presented for recognition or recall, they were less likely to evoke an in- 
terdependent network of visual and verbal associations in the poor readers. The poor readers' pattern of performance on the working memory tasks (McNeil \& Johnston, 2004), where they showed a lack of phonological coding when presentation was pictorial, may therefore stem from fewer or degraded interconnections between the visual and the verbal representations as a result of these systems being poorly coordinated, thus producing a reliance on intact visual processes. Evidence that their visual skills were intact is shown by their scores on the WISC Performance IQ subtests (Block Design and Object Assembly).

When learning to read new words, poor readers may prefer to use a visual approach, working out what the word is from context or getting the pronunciation of the word from the teacher. Poor readers' phonological representations for printed words in long-term memory may, therefore, be incomplete-hence, the difficulty in accessing this information. Thus, the failure to develop visual-phonological linkages in acquisition may stem, in part, from a bias toward a visual approach to reading. In the early stages of acquisition, normal readers, to some degree, similarly fail to use visual and verbal codes in integrative fashion, reading logographically or by an incomplete alphabetic approach (Ehri, 1992). The poor readers in the present study may have initially been very successful with such an approach, because their visual skills were relatively good, and may not have felt the need to develop a form of word recognition heavily underpinned by phonological information. Other poor readers having a severe underlying phonological deficit may focus even more on orthography in reading, as a means of compensating for their phonological weaknesses. Consequently, an orthographic-processing bias may stem from intact visual skills for some poor readers but, for others, may be due to very weak underlying phonological skills. Despite a match for RA, one can only assume that these poor readers' phonological skills would have been much poorer 4 years earlier (i.e., when at the same age as that of the present RA controls). Accordingly, visual encoding may have been the only viable strategy for reading, and this approach may have become more pervasive as their phonological skills continued to fall behind. Either way, the issue of causality cannot be resolved in the absence of longitudinal data.

In conclusion, it appears that although the poor readers were capable of taking a phonological approach to reading, they nonetheless demonstrated a bias toward establishing visual memory codes for printed words, failing to integrate these representations with the corresponding phonological forms. The result was that the poor readers had good visual recognition of nonwords but that this was not matched by an equivalent ability to read the items. Even when they were taught to read the items, with explicit training in the pronunciation of the vowel digraph, they were much slower than the RA controls to set up connections between the printed form and its pronunciation. Thus, although they had developed both the orthographic-phonological and the orthographic-semantic pathways in reading, the latter may have been better developed and not so well integrated with the former as it was for the RA controls.

\section{AUTHOR NOTE}

The work was conducted while A.M.M. was a PhD student at the University of St. Andrews. We thank the Grade 3 pupils and staff at Glebelands Primary School in Dundee. A special mention is also due the pupils and their teachers at Clermiston and Craiglockhart reading units in Edinburgh for their support and assistance with this and other projects over the years. Correspondence concerning this article should be addressed to R. S. Johnston, Department of Psychology, University of Hull, Hull HU6 7RX, England (e-mail: r.s.johnston@hull.ac.uk).

\section{REFERENCES}

AdAms, M. J., \& BRUCK, M. (1993). Word recognition: The interface of educational policies and scientific research. Reading \& Writing, 5, 113-139.

BADDELEY, A. D. (1986). Working memory. Oxford: Oxford University Press.

Baddeley, A. D., Ellis, N. C., Miles, T. R., \& Lewis, V. J. (1982). Developmental and acquired dyslexia: A comparison. Cognition, 11, 185-199.

Baddeley, A. D., Thomson, N., \& Buchanan, M. (1975). Word length and the structure of short-term memory. Journal of Verbal Learning \& Verbal Behavior, 14, 575-589.

Badian, N. A. (1994). Preschool prediction: Orthographic and phonological skills, and reading. Annals of Dyslexia, 44, 3-25.

BADIAN, N. A. (1995). Predicting reading ability over the long term: The changing roles of letter-naming, phonological awareness and orthographic processing. Annals of Dyslexia, 45, 79-96.

Bailey, C. E., Manis, F. R., Pedersen, W. C., \& Seidenberg, M. S. (2004). Variation among developmental dyslexics: Evidence from a printed-word-learning task. Journal of Experimental Child Psychology, 87, 125-154.

BEECH, J. R., \& AWAIDA, M. (1992). Lexical and nonlexical routes: A comparison between normally achieving and poor readers. Journal of Learning Disabilities, 25, 196-206.

Bishop, D. V. M., \& AdAms, C. (1990). A prospective study of the relationship between specific language impairment, phonological disorders and reading retardation. Journal of Child Psychology \& Psychiatry, 31, 1027-1050.

Bowers, P. G., \& WoLf, M. (1993). Theoretical links among naming speed, precise timing mechanisms and orthographic skill in dyslexia. Reading \& Writing, 5, 69-85.

Brady, S., Shankweiler, D., \& Mann, V. A. (1983). Speech perception and memory coding in relation to reading ability. Journal of Experimental Child Psychology, 35, 345-367.

BRUCK, M., \& Treiman, R. (1990). Phonological awareness and spelling in normal children and dyslexics: The case of initial consonant clusters. Journal of Experimental Child Psychology, 50, 156-178.

Carroll, J. B., Davies, P., \& Richman, B. (1971). The word frequency book. New York: American Heritage.

Coltheart, M. (1978). Lexical access in simple reading tasks. In G. Underwood (Ed.), Strategies of information processing (pp. 151-216). London: Academic Press.

Duncan, L. G., \& Johnston, R. S. (1999). How does phonological awareness relate to nonword reading skill amongst poor readers? Reading \& Writing, 11, 405-439.

EHRI, L. C. (1992). Reconceptualizing the development of sight word reading and its relationship to recoding. In P. B. Gough, L. C. Ehri, \& R. Treiman (Eds.), Reading acquisition (pp. 107-143). Hillsdale, NJ: Erlbaum.

Elliott, C. D., Murray, D. J., \& Pearson, L. S. (1977). The British Abilities Scales. Windsor, U.K.: NFER Nelson.

Ellis, N. [C.] (1981). Visual and name coding in dyslexic children. Psychological Research, 43, 201-218.

Foorman, B., \& Liberman, D. (1989). Visual and phonological processing of words: A comparison of good and poor readers. Journal of Learning Disabilities, 22, 349-355.

Frith, U., \& SNOWLING, M. (1983). Reading for meaning and reading for sound in autistic and dyslexic children. British Journal of Developmental Psychology, 1, 329-342.

Harm, M. W., \& SeIdenberg, M. S. (1999). Phonology, reading acquisi- 
tion, and dyslexia: Insights from connectionist models. Psychological Review, 106, 491-528.

Harm, M. W., \& SEIDENBERG, M. S. (2004). Computing the meanings of words in reading: Cooperative division of labor between visual and phonological processes. Psychological Review, 111, 662-720.

Hitch, G. J., Halliday, M. S., DodD, A., \& LitTleR, J. E. (1989). Development of rehearsal in short-term memory: Differences between pictorial and spoken stimuli. British Journal of Developmental Psychology, 7, 347-362.

Holligan, C., \& Johnston, R. S. (1988). The use of phonological information by good and poor readers in memory and reading tasks. Memory \& Cognition, 16, 522-532.

Johnston, R. S., Anderson, M., Perrett, D. I., \& Holligan, C. (1990). Perceptual dysfunction in poor readers: Evidence for visual and auditory segmentation problems in a sub-group of poor readers. British Journal of Educational Psychology, 60, 212-219.

JoRM, A. F. (1983). Specific reading retardation and working memory: A review. British Journal of Psychology, 74, 311-342.

Jorm, A. F., \& Share, D. L. (1983). Phonological recoding and reading acquisition. Applied Psycholinguistics, 4, 103-147.

Macaruso, P., Locke, J. L., Smith, S. T., \& Powers, S. (1996). Shortterm memory and phonological coding in developmental dyslexia. Journal of Neurolinguistics, 9, 135-146.

Manis, F. R., Custodio, R., \& Szeszulski, P. A. (1993). Development of phonological and orthographic skill: A 2-year longitudinal study of dyslexic children. Journal of Experimental Child Psychology, 56, 64-86.

Manis, F. R., Seidenberg, M. S., Doi, L. M., McBride-Chang, C., \& Petersen, A. (1996). On the bases of two subtypes of development dyslexia. Cognition, 58, 157-195.

MAXWELL, A. E. (1959). A factor analysis of the Wechsler intelligence scale for children. British Journal of Educational Psychology, 29, 237-241.

McDougall, S., Hulme, C., Ellis, A., \& MonK, A. (1994). Learning to read: The role of short term memory and phonological skills. Journal of Experimental Child Psychology, 58, 112-133.

McNeIL, A. M., \& Johnston, R. S. (2004). Word length, phonemic, and visual similarity effects in poor and normal readers. Memory \& Cognition, 32, 687-695.

Metsala, J. L., Stanovich, K. E., \& Brown, G. D. A. (1998). Regularity effects and the phonological deficit model of reading disabilities: A meta-analytic review. Journal of Educational Psychology, 90, 279-293.

Olson, R. K., Kliegl, R., Davidson, B. J., \& Foltz, G. (1985). Individual and developmental differences in reading disability. In G. E. MacKinnon \& T. G. Waller (Eds.), Reading research: Advances in theory and practice (Vol. 4, pp. 1-64). New York: Academic Press.

Olson, R. K., Wise, B., ConNors, F., Rack, J., \& FulKer, D. (1989). Specific deficits in component reading and language skills: Genetic and environmental influences. Journal of Learning Disabilities, 22, 339-348.

Plaut, D. C., McClelland, J. L., Seidenberg, M. S., \& Patterson, K. [E.] (1996). Understanding normal and impaired word reading: Computational principles in quasi-regular domains. Psychological Review, 103, 56-115.

RACK, J. P. (1985). Orthographic and phonetic coding in developmental dyslexia. British Journal of Psychology, 76, 325-340.

Rack, J. P., Snowling, M. J., \& Olson, R. K. (1992). The nonword reading deficit in developmental dyslexia: A review. Reading Research Quarterly, 27, 28-53.
SATtLER, J. M. (1982). Assessment of children's intelligence and special abilities. Boston: Allyn \& Bacon.

Scarborough, H. S. (1989). Prediction of reading disability from familial and individual differences. Journal of Educational Psychology, 81, 101-108.

Seidenberg, M. S., \& McClelland, J. L. (1989). A distributed, developmental model of word recognition and naming. Psychological Review, 96, 523-568.

Seidenberg, M. S., Waters, G. S., Barnes, M. A., \& Tanenhaus, M. K. (1984). When does irregular spelling or pronunciation influence word recognition? Journal of Verbal Learning \& Verbal Behavior, 23, 383-404.

Seymour, P. H. K., \& Porpodas, C. (1980). Lexical and non-lexical processing of spelling in dyslexia. In U. Frith (Ed.), Cognitive processes in spelling (pp. 444-473). London: Academic Press.

Siegel, L. S., Share, D., \& Geva, E. (1995). Evidence for superior orthographic skills in dyslexics. Psychological Science, 6, 250-254.

SNowling, M. J. (1980). The development of grapheme-phoneme correspondence in normal and dyslexic readers. Journal of Experimental Child Psychology, 29, 294-305.

SnOwling, M. J. (1981). Phonemic deficits in developmental dyslexia. Psychological Research, 43, 219-234.

Stanovich, K. E., Cunningham, A. E., \& Cramer, B. B. (1984). Assessing phonological awareness in kindergarten children: Issues of task comparability. Journal of Experimental Child Psychology, 38, 175-190.

Stanovich, K. E., \& Siegel, L. S. (1994). Phenotypic performance profile of children with reading disabilities: A regression-based test of the phonological-core variable-difference model. Journal of Educational Psychology, 86, 24-53.

Swanson, H. L. (1984). Semantic and verbal memory codes in learning disabled readers. Journal of Experimental Child Psychology, 37, 124-140.

SWANSON, H. L. (1987). Verbal coding deficits in learning disabled readers: Remembering pictures and words. Advances in Learning \& Behavioural Disabilities, 2(Suppl.), 263-304.

Vellutino, F. R. (1979). Dyslexia: Theory and research. Cambridge, MA: MIT Press.

Vellutino, F. R., Pruzek, R., Steger, J. A., \& Meshoulam, U. (1973). Immediate visual recall in poor readers as a function of orthographic-linguistic familiarity. Cortex, 9, 368-384.

Waters, G. S., Seidenberg, M. S., \& Bruck, M. (1984). Children's and adults' use of spelling-sound information in three reading tasks. Memory \& Cognition, 12, 293-305.

WECHSLER, D. (1974). Wechsler Intelligence Scale for Children: Revised. New York: Psychological Corporation.

Wolf, M., \& Goodglass, H. (1986). Dyslexia, dysnomia, and lexical retrieval: A longitudinal investigation. Brain \& Language, 28, 154-168.

Yopp, H. K. (1988). The validity and reliability of phoneme awareness tests. Reading Research Quarterly, 23, 159-177.

\section{NOTE}

1. Within the text, the terms visual and verbal are used to describe the approaches taken to encode information that is presented either visually or auditorily. Where this information involves print, the term orthographic might be used in place of visual, and where it involves a picturable object, pictorial. The terms verbal and phonological are also used interchangeably and apply equally to situations in which a visual stimulus (e.g., a printed word or picture) is present or absent (as with spoken presentation alone). 
APPENDIXA

Four Stimulus Sets Counterbalanced in Nonword Acquisition Task

\begin{tabular}{lllll}
\hline & Set 1 & Set 2 & \multicolumn{1}{c}{ Set 3 } & \multicolumn{1}{c}{ Set 4 } \\
\hline Orthographically similar & gaboatok & renoudel & yamoiter & nuraipog \\
& ganoatok & revoudel & yajoiter & nukaipog \\
& gapoatok & rekoudel & yakoiter & numaipog \\
Orthographically dissimilar & renoudel & yajoiter & numaipog & gaboatok \\
& yamoiter & nukaipog & gapoatok & revoudel \\
& nuraipog & ganoatok & rekoudel & yakoiter \\
\hline
\end{tabular}

APPENDIX B

Target Items and Four Distractors Used in Visual Recognition Memory Task (As Shown in Testing 4b)

\begin{tabular}{lllll}
\hline & \multicolumn{5}{c}{ Distractors } \\
\cline { 2 - 5 } Target Items & \multicolumn{1}{c}{ 1 } & 2 & 3 & 4 \\
\hline gaboatok & gabaotok & gabowtok & faboatok & gaboatot \\
ganoatok & ganaotok & ganowtok & paboatok & ganoatob \\
gapoatok & gapaotok & gapowtok & rapoatok & gapoatof \\
renoudel & renuodel & renoodel & tenoudel & renodek \\
revoudel & revuodel & revoodel & levoudel & revoudet \\
rekoudel & rekuodel & rekoodel & pekoudel & rekoudef \\
yamoiter & yamioter & yamoyter & kamoiter & yamoiten \\
yajoiter & yajioter & yajoyter & pajoiter & yajoitep \\
yakoiter & yakioter & yakoyter & jakoiter & yakoitem \\
nuraipog & nuriapog & nuraypog & muraipog & nuraipoy \\
nukaipog & nukiapog & nukaypog & tukaipog & nukaipok \\
numaipog & numiapog & numaypog & humaipog & numaipon \\
\hline
\end{tabular}

$\overline{\text { Note-Boldface indicates how the distractor item differed from the }}$ target.

\begin{tabular}{ccccc}
\multicolumn{4}{c}{$\begin{array}{c}\text { APPENDIX C } \\
\text { Regularity Task }\end{array}$} \\
\cline { 1 - 2 } \cline { 5 - 5 } \cline { 5 - 5 } Irregular Words & & \multicolumn{2}{c}{ Regular Words } \\
\hline High Frequency & Low Frequency & & High Frequency & Low Frequency \\
\hline heard & pint & & best & rub \\
good & soul & & green & spear \\
foot & touch & & bring & gang \\
bread & steak & & stick & spade \\
great & bush & & still & luck \\
both & sew & & take & dive \\
does & deaf & & dance & dust \\
gone & aunt & & turn & wake \\
shall & wool & & down & treat \\
give & doll & & went & stuck \\
bowl & prove & & hard & pest \\
come & glove & & got & base \\
love & broad & kept & mile \\
put & lose & strong & slate \\
\hline
\end{tabular}


APPENDIX D

Auditory Rhyme Judgment Task

\begin{tabular}{|c|c|c|c|}
\hline \multicolumn{2}{|c|}{ Rhyming } & \multicolumn{2}{|c|}{ Nonrhyming } \\
\hline $\begin{array}{l}\text { Orthographically } \\
\text { Similar }\end{array}$ & $\begin{array}{l}\text { Orthographically } \\
\text { Dissimilar }\end{array}$ & $\begin{array}{c}\text { Orthographically } \\
\text { Similar }\end{array}$ & $\begin{array}{l}\text { Orthographically } \\
\text { Dissimilar }\end{array}$ \\
\hline gate-late & wait-mate & deaf-leaf & beat-harp \\
\hline bake-cake & soak-coke & move-love & pins-side \\
\hline wing-ring & bowl-coal & warn-barn & pair-fake \\
\hline long-song & rule-fool & want-pant & soap-code \\
\hline sick-pick & case-face & work-fork & wail-mats \\
\hline rice-mice & coat-note & does-goes & tame-paid \\
\hline farm-harm & pies-size & post-cost & cave-mail \\
\hline gift-lift & hole-goal & warm-harm & pair-fake \\
\hline plan-flan & clue-flew & pint-mint & club-fled \\
\hline horn-born & paid-fade & most-lost & hope-goat \\
\hline burn-turn & base-race & done-gone & cast-fact \\
\hline hand-sand & pain-lane & wolf-golf & bare-rake \\
\hline sold-bold & tail-pale & wear-dear & rude-foal \\
\hline land-band & bear-hare & gone-lone & cost-none \\
\hline gown-down & pour-sore & pear-year & poor-sort \\
\hline
\end{tabular}

Note-Items in boldface represent original items subsequently removed from the analysis.

APPENDIX E

Phoneme Deletion Task

\begin{tabular}{|c|c|c|c|c|c|c|c|}
\hline \multicolumn{4}{|c|}{ Words } & \multicolumn{4}{|c|}{ Nonwords } \\
\hline $\mathrm{C} / \mathrm{VCC}$ & $\mathrm{C} / \mathrm{CVC}$ & $\mathrm{CCV} / \mathrm{C}$ & $\mathrm{CVC} / \mathrm{C}$ & $\mathrm{C} / \mathrm{VCC}$ & $\mathrm{C} / \mathrm{CVC}$ & $\mathrm{CCV} / \mathrm{C}$ & $\mathrm{CVC} / \mathrm{C}$ \\
\hline hard & floor & scale & salt & fard & froash & spale & nolp \\
\hline cost & blood & stood & most & nost & klud & spoot & koasp \\
\hline wild & flat & small & learn & jild & smab & snol & ferm \\
\hline next & brown & breath & desk & lext & trown & preath & besk \\
\hline mind & grass & class & must & gind & prass & blass & nust \\
\hline work & step & sleep & turn & durk & skep & smell & purm \\
\hline
\end{tabular}

(Manuscript received March 1, 2004;

revision accepted for publication August 5, 2007.) 